\title{
Exergetic Comparison of Electrical Heating Gasification and Water Electrolysis Assisted Gasification for Renewable Electricity Storage
}

\begin{abstract}
Guohui Song, ${ }^{\mathrm{a}, *}$ Haiqing Qiao, ${ }^{\mathrm{b}}$ Haiming Gu, ${ }^{\mathrm{a}}$ and Xiaobo Cui ${ }^{\mathrm{a}, \mathrm{c}}$
To develop an efficient solution for the storage of renewable electricity and utilization of biomass or waste within the power-to-X concept, the electrical heating gasification (EHG) technology for industrial-scale application was proposed and compared with water electrolysis-assisted gasification (WEG). The two technologies were compared in terms of composition, yield, and exergy efficiency. The results indicate that EHG consumes less electricity and generates syngas with higher chemical exergy. The maximum exergy efficiency of EHG was calculated as $80.76 \%$. Electrical heating gasification is more efficient than WEG based on either the current state or the potential progress in the future. Additionally, the exergy efficiency of water electrolysis ranges between $54.1 \%$ and $79.1 \%$, which implies that more efforts are needed in the future to reduce the specific electricity consumption. This work is valuable to guide the development of an electrical heating gasifier and to improve performances of power-to-X technologies.
\end{abstract}

DOI: 10.15376/biores.17.1.993-1000

Keywords: Gasification; Electrical heating; Water electrolysis; Exergy analysis; Renewable electricity storage

Contact information: a: School of Energy and Power Engineering, Nanjing Institute of Technology, Nanjing 211167 China; b: Qingdao Product Quality Test Research Center, Qingdao 266101 China; c: School of Energy and Environment, Southeast University, Nanjing 210096 China;

* Corresponding author: ghsong@njit.edu.cn

\section{INTRODUCTION}

Renewable electricity storage plays a critical role in maintaining a robust and reliable modern electricity system. Power-to- $X$ is emerging as a viable platform for storing excess renewables. The product $\mathrm{X}$ can be syngas, methane, or methanol. The carbon source can be biogas, syngas, or other $\mathrm{CO}_{2}$ sources extracted from power plants, industrial processes, etc. (Bailera et al. 2017; Ghaib and Ben-Fares 2018). Biomass is widely available across the world and has less environmental impacts, ensuring that most communities can benefit spatially, financially, and environmentally. Thus, using biomass within power-to- $X$ is of great practical value.

When biomass is used as carbon source, gasification is the key step for sustainable fuels production. The oxygen-steam gasification is commonly integrated to utilize the oxygen generated by water electrolysis (Mesfun et al. 2019). The integrated process is named as water electrolysis-assisted gasification (WEG) in this work. However, the energy efficiencies of such electrolyzers varies extensively from 62\% to 90\% (Schmidt et al. 2017; Dawood et al. 2020). There is plenty of energy loss during water electrolysis. Thus, the 
ways to reduce specific electricity consumption are of great significance for this technical route.

A key to minimizing the amount of required energy is to take full advantage of integrating those unit operations with other processes that are already taking place within the same industrial facilities (Hubbe 2021). With the aim to use biomass for renewable electricity storage, all electricity-driven technologies can be considered for biomass gasification, such as microwave heating (Wang et al. 2016), and plasma torch (Rutberg et al. 2011; Ram et al. 2021), etc. Electrical heating technologies are efficient, mature, and have been widely used in various industrial processes. The energy efficiency of ohmic heating and resistance heating can reach $97 \%$ and approximately $100 \%$, respectively (Sakr and Liu 2014). Although resistance heating is often used in biomass gasifiers at an experimental scale, there have been few studies on applications of the technologies on biomass gasification on an industrial scale (Zhao et al. 2020). Therefore, using electrical heating to drive the biomass gasification process is a potentially promising way to improve energy efficiency. Exergy is defined as the amount of work a system can be perform when it is brought into thermodynamic equilibrium with its environment. As electricity can completely be converted into work, it is reasonable to use the concept of exergy to evaluate such an electricity-driven process.

Motivated by the above analyses, the objective of this work was to evaluate and compare electrical heating gasification with water electrolysis-assisted gasification. The processes are modeled using Aspen Plus software, and the composition, yield, and exergy analysis are investigated. It is expected to offer an alternative and efficient solution for renewable electricity storage and biomass management.

\section{CONFIGURATIONS AND METHODOLOGY}

\section{Process Configuration}

Figure 1(a) shows the process configuration of WEG. It mainly consists of two parts: water electrolysis (WE) and oxygen-steam gasification (OSG). Dried biomass is converted into producer gas, tars, residual char, and ash via gasification process using oxygen and steam as gasifying agents. Then, the producer gas is cooled to ambient temperature and cleaned by the cooling and cleaning unit (CC), where the heat with temperature greater than $80{ }^{\circ} \mathrm{C}$ is recovered.
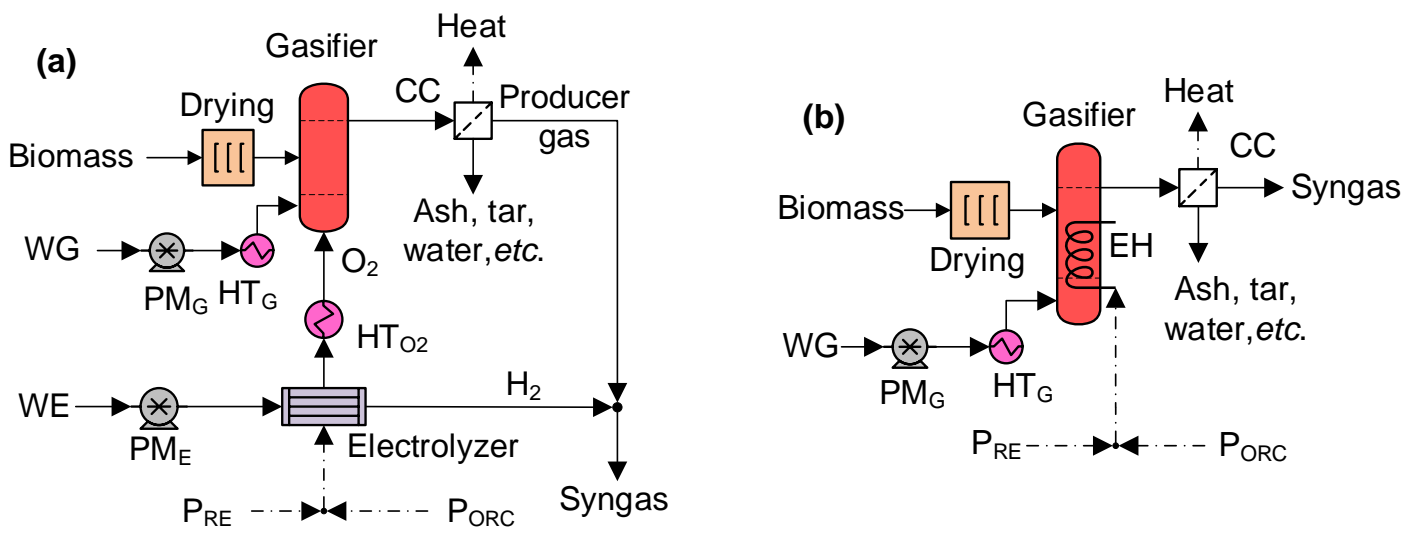

Fig. 1. Process configurations of (a) WEG and (b) EHG 
Part of the recovered heat is used for biomass drying and the preheating of gasify agents. The water for gasification (WG) and the oxygen are preheated to $200{ }^{\circ} \mathrm{C}$ by the heaters $\mathrm{HT}_{\mathrm{G}}$ and $\mathrm{HT}_{\mathrm{O}}$, respectively. The residual heat is utilized in two ways. The first way is to generate steam at $200{ }^{\circ} \mathrm{C}$; the second way is to generate electricity by the Organic Rankine Cycle (ORC) to compensate partial electricity consumed by the process.

The water electrolysis unit driven by renewable power $\left(P_{\mathrm{RE}}\right)$ generates oxygen for OSG. The hydrogen generated in this unit is assumed to mix with producer gas to generate syngas in this study. Alternatively, producer gas and $\mathrm{H}_{2}$ stream can be separately used. Today, the energy efficiencies of various electrolyzers ( $\eta \mathrm{wE}$ ) range from $62 \%$ to $90 \%$ based on higher heating value of $\mathrm{H}_{2}$ (Dawood et al. 2020). Thus, $\eta$ we over 65 to $95 \%$ with the typical value of $85 \%$ was investigated as the important variable of WEG. The $\eta$ wE of $95 \%$ was considered for future technical progress.

Figure 1(b) indicates the process configuration of EHG, which is similar to but simpler than that of WEG. Only steam gasification is applied during the EHG process, and the required heat is completely supplied by electrical heating. The electrical heating technology includes various electricity to heat technologies such as resistance heating, arc furnaces, microwave processing, plasma processing, etc. (U.S. Department of Energy 2016). This work did not specify the electrical heating technology; instead, the energy efficiency of electricity-to-heat conversion $(\eta \mathrm{EH})$ over 70 to $99 \%$ was investigated as the important variable to represent the theoretical performance of various electrical heating technologies. The typical value of $\eta \mathrm{EH}$ was set to $99 \%$ considering the potential application of resistance heating.

Based on previous studies, the gasifier is assumed to be operated at atmospheric pressure, gasification temperature of $800{ }^{\circ} \mathrm{C}$, and a steam/biomass mass ratio of 0.5 . In addition, heat dissipation accounts for $3 \%$ of input energy of biomass based on lower heating value. The simulations were performed based on the established models including steam gasification and producer gas cooling cleaning, and biomass and power-to-gas processes, including oxygen-steam gasification (Song et al. 2013, 2021). Briefly, it was assumed that all reactors are operated under a steady state and that residence times are long enough for the reactions to reach chemical equilibrium. Ash in biomass does not participate in any chemical reactions. The carbon conversion efficiency of the feedstock was $99 \%$. The amount of oxygen for OSG in WEG or the required power for electrical heating in EHG were calculated by the use-defined subroutines via Aspen Plus 10.1 (AspenTech, Bedford, MA, U.S.). The net efficiency of ORC was set to $25 \%$. The gasification simulations had been verified in the authors' previous studies (Song et al. 2013, 2021).

\section{Exergy Analyses}

Wheat straw was the feedstock (Qingdao Product Quality Test Research Center, Qingdao, China). The composition data are listed in Table 1 and the specific chemical exergy of biomass (SCE) is calculated to be $17758 \mathrm{~kJ} / \mathrm{kg}$ on an air-dried basis (Song et al. 2012).

Table 1. Composition Data and Specific Chemical Exergy of the Feedstock

\begin{tabular}{|c|c|c|c|c|c|c|c|c|}
\hline \multicolumn{4}{|c|}{ Proximate Analysis (wt\%) } & \multicolumn{5}{c|}{ Ultimate Analysis (wt\%) } \\
\hline Moisture & $\begin{array}{c}\text { Fixed } \\
\text { Carbon }\end{array}$ & $\begin{array}{c}\text { Volatile } \\
\text { Matter }\end{array}$ & Ash & Carbon & Hydrogen & Nitrogen & Sulfur & Oxygen \\
\hline 5.46 & 19.42 & 68.59 & 6.53 & 41.99 & 5.58 & 0.61 & 0.28 & 39.55 \\
\hline
\end{tabular}


Two exergy efficiencies are defined according to the final products. The first is cogeneration of syngas and steam, and the overall exergy efficiency $(\varepsilon 1, \%)$ is defined as follows in Eq. 1,

$$
\varepsilon_{1}=\frac{E x_{\text {syngas }}+E x_{\text {steam }}}{E x_{\text {bio }}+3.6 P_{\mathrm{T}}} \times 100 \%
$$

where $E x_{\text {sygngas }}$ and $E x_{\text {steam }}$ are exergy flow rates of syngas and steam generated by recovered heat, respectively $(\mathrm{MJ} / \mathrm{h}), E x_{\text {bio }}$ is the exergy flow rate of biomass $(\mathrm{MJ} / \mathrm{h})$, and $P_{\mathrm{T}}$ is the total electrical power consumed by the process $(\mathrm{kW})$. Ex $x_{\text {sygngas }}$ is calculated based on the specific chemical exergies of the components in syngas (Song et al. 2021).

The second overall exergy efficiency $(\varepsilon 2, \%)$ only involves syngas as the final product, and surplus recovered heat is used to generate power by ORC. It is defined as follows in Eq. 2,

$$
\varepsilon_{2}=\frac{E x_{\text {syngas }}}{E x_{\text {bio }}+3.6\left(P_{\mathrm{T}}-P_{\mathrm{ORC}}\right)}
$$

where $P_{\mathrm{ORC}}$ is the power generated by the surplus recovered heat using $\mathrm{ORC}(\mathrm{kW})$.

\section{RESULTS AND DISCUSSION}

\section{Compositions and Yields}

The compositions and yields of WEG and EHG are listed in Table 1. Due to the absence of oxygen, the syngas of EHG had a higher $\mathrm{CO}$ content and lower $\mathrm{CO}_{2}$ content compared with syngas of WEG. Due to the addition of $\mathrm{H}_{2}$ generated by WE, $\mathrm{H}_{2}$ concentration in syngas of WEG was higher than that of EHG. The $S C E_{\text {syngas }}$ of EHG was still visibly greater than that of WEG, because the total concentration of flammable species in syngas of EHG was higher than that of WEG. Additionally, EHG had a slight disadvantage in syngas yield.

\begin{tabular}{|c|c|c|c|c|c|c|c|c|c|}
\hline \multirow{2}{*}{ Syngas } & \multicolumn{5}{|c|}{ Composition (\%) } & \multirow{2}{*}{$\begin{array}{c}\text { SCE } \\
\left(\mathrm{MJ} / \mathrm{Nm}^{3}\right)\end{array}$} & \multirow{2}{*}{$\begin{array}{c}\text { Yield } \\
\left(\mathrm{Nm}^{3} / \mathrm{kg}_{\text {daf }}\right)\end{array}$} & \multirow{2}{*}{$\varepsilon_{1}(\%)$} & \multirow{2}{*}{$\varepsilon_{2}(\%)$} \\
\hline & $\mathrm{CH}_{4}$ & $\mathrm{H}_{2}$ & $\mathrm{CO}$ & $\mathrm{CO}_{2}$ & $\mathrm{~N}_{2}$ & & & & \\
\hline WEG & 5.43 & 50.83 & 26.47 & 16.87 & 0.31 & 10.62 & 1.822 & 75.89 & 73.34 \\
\hline EHG & 5.9 & 46.6 & 37.35 & 9.71 & 0.33 & 11.68 & 1.678 & 80.76 & 78.90 \\
\hline
\end{tabular}

Table 2. Compositions, Yields, and Exergy Efficiencies of WEG and EHG

\section{Exergy Flows and Losses}

The exergy flows and losses of WEG and EHG per kg of biomass are as shown in Fig. 2(a) and (b), respectively. With respect to WEG, complex processes take place in OSG, such as oxidation reactions, heat transfers, pyrolysis, and reforming reactions. The exergy loss due to heat dissipation (HD) of the gasifier was $0.34 \mathrm{MJ}$. The sum of other exergy losses was $3.58 \mathrm{MJ}$, including intrinsic exergy losses in the gasifier and other auxiliary devices. The exergy efficiency of OSG was approximately 78\%. More importantly, the exergy loss in WE was as high as $1.84 \mathrm{MJ}$, and its exergy efficiency ( $\varepsilon \mathrm{wE}$ ) was $70.8 \%$, which was approximately $14 \%$ less than $\eta$ we $(85 \%)$. The authors further checked the variation of $\varepsilon \mathrm{WE}$ with $\eta \mathrm{WE}$ over 65 to $95 \%$. The results show that $\varepsilon \mathrm{WE}$ sat between $54.1 \%$ and $79.1 \%$, and the difference between the exergy and energy efficiencies varied from 10.9 to 15.9 percentage points, which gradually increased with the increase in $\eta$ we. These 
indicate that when electrolysis of water is evaluated by exergy, more researches should be carried out to improve the efficiency.

Concerning EHG, Fig. 2(b) indicates that the exergy loss in electricity-to-heat conversion was small (0.05 MJ). Other exergy losses of EHG (3.98 MJ) were approximately 0.4 MJ greater than that of WEG. Compared with WEG, EHG consumed less renewable electricity (4.84 MJ) and generated syngas with greater chemical exergy $(17.70 \mathrm{MJ})$. Figure 2 also clearly shows that the water electrolysis process is the main reason causing the difference of the total exergy loss between EHG and WEG.

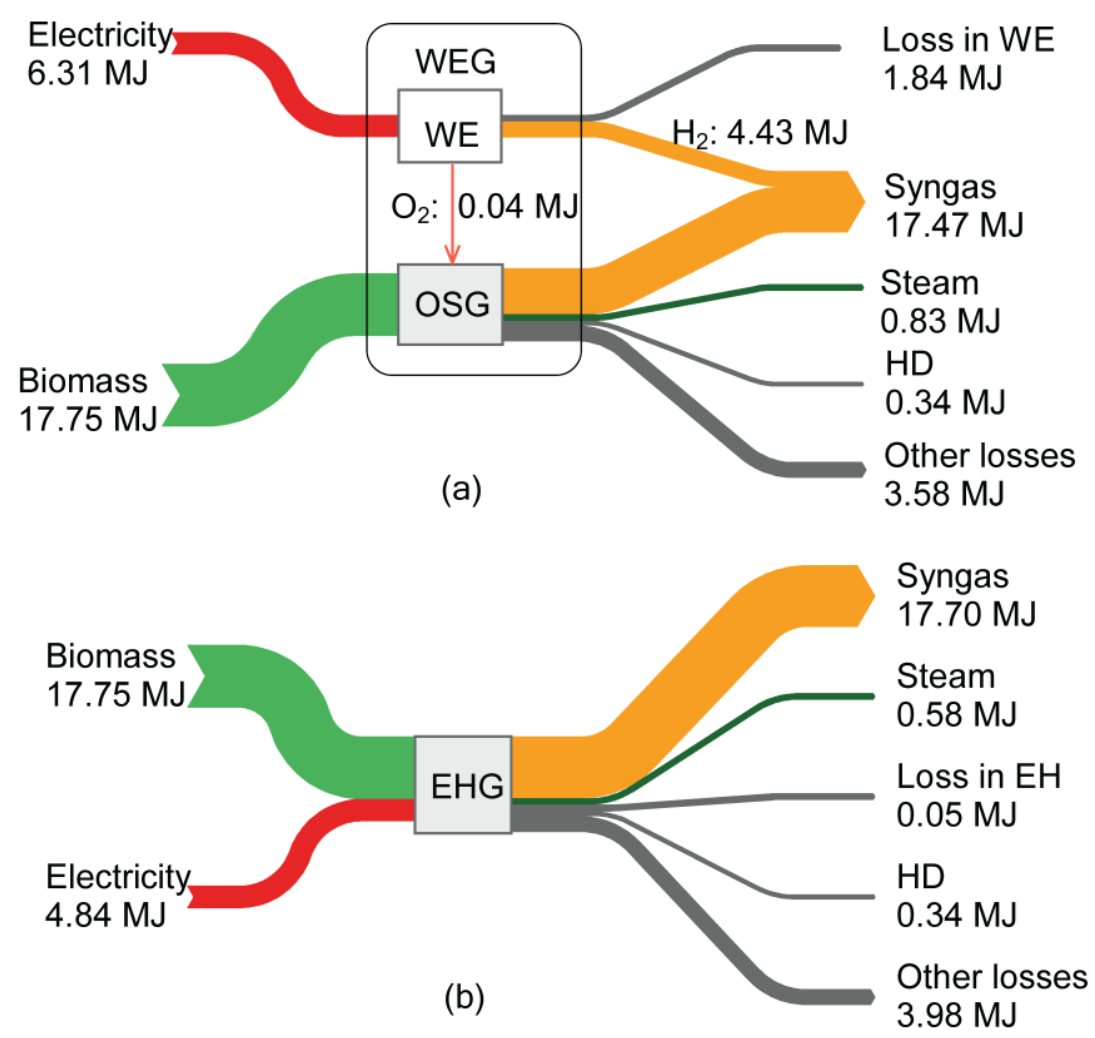

Fig. 2. Exergy flows and losses of (a) WEG with $\eta_{\text {WE }}$ of $85 \%$ and (b) EHG with $\eta_{E H}$ of $99 \%$

\section{Effects of $\eta_{\mathrm{WE}}$ and $\eta_{\mathrm{EH}}$}

Table 2 shows that either $\varepsilon_{1}$ or $\varepsilon_{2}$ of WEG at $\eta$ wE of $85 \%$ was approximately 5 percentage points lower than that of EHG at $\eta_{\mathrm{EH}}$ of $99 \%$. Further, Fig. 3 shows that both $\varepsilon 1$ and $\varepsilon_{2}$ approximatively have linear function relation with $\eta$ wE or $\eta_{\mathrm{EH}}$. The maximum values of $\varepsilon 1$ and $\varepsilon_{2}$ of WEG are $78.04 \%$ and $75.44 \%$, respectively, while those of EHG are $80.76 \%$ and $78.90 \%$, respectively. At the current state and in the near future ( $\eta \mathrm{wE} \leq 95 \%)$, when $\eta$ EH exceeds $87 \%, \varepsilon 1$,EHG is always greater than $\varepsilon 1$,WEG; while when $\eta$ EH exceeds $83 \%, \varepsilon 2$,EHG is always greater than $\varepsilon 2$,WEG. Additionally, $\varepsilon 1$,EHG and $\varepsilon 2$,EHG are on average 2.2 and 2.9 percentage points higher than those of WEG with the same values of $\eta \mathrm{wE}$ and $\eta \mathrm{EH}$, respectively. It can be inferred that even if $\eta$ wE could achieve $99 \%$, EHG would still have an obvious advantage over WEG in exergy efficiency. These comfirm that electrical heating gasification is an efficient techology within the framework of power-to-X using biomass or wastes as carbon source.

Facing the demand of large-scale renewable power storage via power-to-X pathway, the mature electrical heating technologies can play an alternative and attractive 
role in biomass or wastes gasification. Based on the authors' experiences, EHG probably has disadvantages in heat and mass transfers since the radiative heat transfer is the major way and the amount of gasify agent may be not sufficient to enhance the transfers. Additionally, the presence of alkaline ash may pose great challenges to the surface of the electrical heating parts. In the future, the electrical heating gasifier should be comprehensively developed based on the selected electrical heating technology, such as enhancing mass and heat transfers, accelerating reaction rate, high-temperature corrosion and protection, etc. It is worth promoting the application of electrical heating gasification within a power-to-X concept.
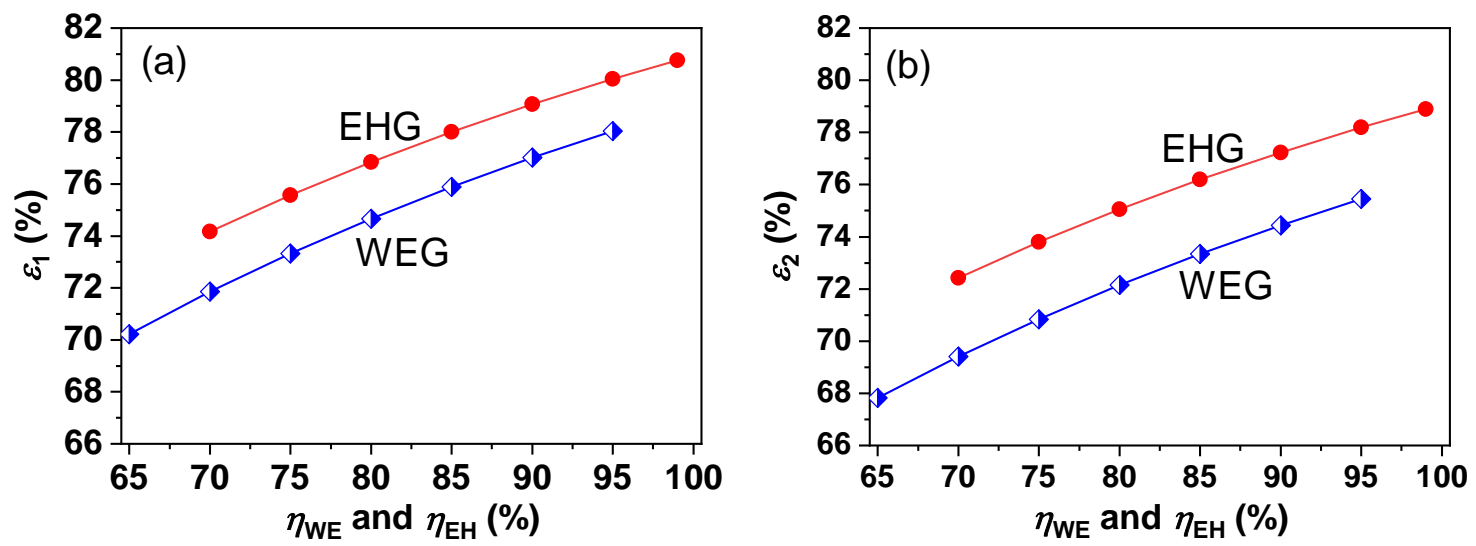

Fig. 3. Variations of (a) $\varepsilon_{1}$ and (b) $\varepsilon_{2}$ with $\eta_{W E}$ and $\eta_{E H}$

\section{CONCLUSIONS}

1. For the same mass flow rate of feedstock, electrical heating gasification (EHG) consumes less electricity and generates syngas with higher chemical exergy value compared with water electrolysis-assisted gasification (WEG), although the yield of EHG is slightly less.

2. The maximum values of $\varepsilon_{1}$ and $\varepsilon_{2}$ of EHG are $80.76 \%$ and $78.90 \%$, respectively. When $\eta \mathrm{EH}$ exceeds $87 \%$, exergy efficiency of EHG is always higher than that of WEG under current or future scenarios.

3. The exergy loss in water electrolysis is large and its exergy efficiency ranges from $54.1 \%$ to $79.1 \%$. More effects should be made to improve the efficiency of water electrolysis.

\section{ACKNOWLEDGMENTS}

This work was financially supported by the Scientific Foundation of Nanjing Institute of Technology (YKJ201818). 


\section{REFERENCES CITED}

Bailera, M., Lisbona, P., Romeo, L. M., and Espatolero, S. (2017). "Power to gas projects review: Lab, pilot and demo plants for storing renewable energy and $\mathrm{CO}_{2}$,"

Renewable and Sustainable Energy Reviews 69, 292-312. DOI:

10.1016/j.rser.2016.11.130

Dawood, F., Anda, M., and Shafiullah, G. M. (2020). "Hydrogen production for energy: An overview," International Journal of Hydrogen Energy 45(7), 3847-3869. DOI: 10.1016/j.ijhydene.2019.12.059

Ghaib, K., and Ben-Fares, F. Z. (2018). "Power-to-Methane: A state-of-the-art review," Renewable and Sustainable Energy Reviews 81(Part 1), 433-446. DOI: 10.1016/j.rser.2017.08.004

Hubbe, M. A. (2021). "Energy efficiency - A particular challenge for the cellulose-based products industries," BioResources 16(4), 6556-6559. DOI:

10.15376/biores.16.4.6556-6559

Mesfun, S., Lundgren, J., Toffolo, A., Lindbergh, G., Lagergren, C., and Engvall, K. (2019). "Integration of an electrolysis unit for producer gas conditioning in a biosynthetic natural gas plant," Journal of Energy Resources Technology 141(1), 1-12. DOI: $10.1115 / 1.4040942$

Ram, C., Kumar, A., and Rani, P. (2021). "Municipal solid waste management: A review of waste to energy (WtE) approaches," BioResources 16(2), 4275-4320. DOI: 10.15376/biores.16.2.Ram

Rutberg, P. G., Bratsev, A. N., Kuznetsov, V. A., Popov, V. E., Ufimtsev, A. A., and Shtengel', S. V. (2011). "On efficiency of plasma gasification of wood residues," Biomass and Bioenergy 35(1), 495-504. DOI: 10.1016/j.biombioe.2010.09.010

Sakr, M., and Liu, S. (2014). "A comprehensive review on applications of ohmic heating (OH)," Renewable and Sustainable Energy Reviews 39, 262-269. DOI: 10.1016/j.rser.2014.07.061

Schmidt, O., Gambhir, A., Staffell, I., Hawkes, A., Nelson, J., and Few, S. (2017). "Future cost and performance of water electrolysis: An expert elicitation study," International Journal of Hydrogen Energy 42(52), 30470-30492. DOI: 10.1016/j.ijhydene.2017.10.045

Song, G., Xiao, J., Zhao, H., and Shen, L. (2012). "A unified correlation for estimating specific chemical exergy of solid and liquid fuels," Energy, 40(1), 164-173. DOI: 10.1016/j.energy.2012.02.016

Song, G., Feng, F., Xiao, J., and Shen, L. (2013). "Technical assessment of synthetic natural gas (SNG) production from agriculture residuals," Journal of Thermal Science 22(4), 359-365. DOI: 10.1007/s 11630-013-0636-8

Song, G., Wang, L., Yao, A., Cui, X., and Xiao, J. (2021). "Technical and economic assessment of a high-quality syngas production process integrating oxygen gasification and water electrolysis: The Chinese case," ACS Omega 6(42), 2785127864. DOI: 10.1021/acsomega.1c03489

U.S. Department of Energy (2016). Improving Process Heating System Performance: A Sourcebook for Industry, Third Edition, Office of Energy Efficiency and Renewable Energy, Washington, DC, U.S.

Wang, X., Qin, G., Chen, M., and Wang, J. (2016). "Microwave-assisted pyrolysis of cotton stalk with additives," BioResources 11(3), 6125-6136. DOI:

10.15376/biores.11.3.6125-6136 
Zhao, L., Yang, Y., Zhou, H., Que, Z., and Pan, Y. (2020). "Ethanol decomposition in supercritical water: An operating parametric experimental and kinetic study," BioResources 15(4), 8515-8528. DOI: 10.15376/biores.15.4.8515-8528

Article submitted: September 4, 2021; Peer review completed: December 11, 2021;

Revised version received and accepted: December 12, 2021; Published: December 16, 2021.

DOI: $10.15376 /$ biores.17.1.993-1000 